\title{
Characterization of U(VI) Sorption-Desorption Processes and Model Upscaling
}

\author{
Gordon E. Brown \\ Department of Geology \\ Stanford University \\ Stanford, CA 94305-2115
}

\section{Introduction and Project Objectives}

In order to apply predictive reactive transport models to the Hanford site, detailed knowledge of the speciation of contaminants is required. Important speciation parameters include: (1) oxidation state; (2) the local molecular structure surrounding contaminant elements; (3) the type and binding of a contaminant ion sorption complex (if adsorbed); (4) the type(s) of phase within which a contaminant is structurally incorporated [e.g., present in a three-dimensional precipitate(s)]; (5) the phase associations of a contaminant; (6) the microscopic distribution of a contaminant within sediments and soils. In the present study, we have used synchrotron-based X-ray spectroscopic methods to study the speciation of $\mathrm{U}$ and $\mathrm{Cu}$ in contaminated soil and sediment samples from the Hanford Site. To complement and complete our initial XAFS investigation of $U$ speciation in contaminated vadose zone sediments below tank BX-102, we have also performed $m X R D$ studies of two sediment sample to identify the specific U(VI)-silicate phase present. Samples from the 300 Area were examined by mSXRF to determine the microscopic distribution and element associations of $\mathrm{Cu}$ and $\mathrm{U}$. These samples were also analyzed by U LIII- and Cu K-edge XAFS spectroscopy to determine the chemical speciation of these elements. Conclusions to Date (1) Uranium occurs primarily as sodium-boltwoodite [Na2(UO2)2(SiO3OH)2-3H2O] in the BX-102 sediment samples. (2) The dissolution kinetics of sodium-boltwoodite will be a major control on the future transport of $U$ beneath tank BX-102. (3) In the 300 Area soils and sediments, uranium occurs as U(VI) and copper as $\mathrm{Cu}(\mathrm{II})$. (4) $\mathrm{U}$ and $\mathrm{Cu}$ are often found together or adjacent to one another; however, these elements don?t appear to be spatially associated with Fe. (5) U appears to be bound to carbonate groups, and is likely contained in a CaCO3 mineral (calcite or aragonite). (6) It is unclear what phase(s) Cu is bound to or associate with, although the data are consistent with an association with CaCO3 minerals. (7) Future U release in the 300 Area will be controlled by the dissolution of $\mathrm{CaCO} 3$ minerals. 